\title{
HPLC Analysis of In-Shell Walnuts for the Natural Incidence and Co-Occurrence of Fusarial Toxins - Zearalenone, Zearalenol and Deoxynivalenol
}

\author{
Rohini Sharma ${ }^{1}$, Geeta Sumbali ${ }^{2}$ \\ ${ }^{1,2}$ Department of Botany, University of Jammu, Jammu-180006, India
}

\begin{abstract}
An investigation was carried out to determine the natural occurrence of some fusarial toxins viz., zearalenone (ZEA), zearalenol (ZAL) and deoxynivalenol (DON) in commercially important in-shell walnut kernels. HPLC analysis showed contamination of ZEA in $63.33 \%$ samples and that of ZAL in 13.33 \% samples. Among the thirty market samples that were investigated, only one sample of in-shell walnuts was found to be contaminated with DON. Co-occurrence of these fusarial toxins was also detected in some of the in-shell samples. Of the samples analysed, 10\% showed co-occurrence of ZEA and ZAL, whereas 3.33\% samples showed cooccurrence of ZEA and DON. In all these samples, the detected amount of ZAL and DON was much higher than that of ZEA.
\end{abstract}

Keywords: Juglans regia, zea, zal, don, mycotoxins.

\section{Introduction}

India has traditionally been one of the world's major producer of edible nuts due to its varied climatic and soil conditions, large domestic markets and relatively simple methods of storage. Among the major edible nuts and dried fruits, walnut (Juglans regia L.) is an important tree nut as every part of the plant has utility and as such has carved its special place in socio- religious and economic well being of the people. It belongs to the angiospermic family Juglandaceae and is commonly called as 'akhroot'. Considerable interest has been generated in walnut as they are believed to possess plasma cholesterol-lowering properties (Sabate et al., 2003). Similarly, concentration of omega-3-fatty acids in walnuts have many potential health benefits ranging from cardiovascular protection to the promotion of better cognitive function to anti- inflammatory benefits helpful in asthma, rheumatoid arthritis and inflammatory skin disease such as eczema and psoriasis. Traditionally, walnuts are used to treat cough, stomach ailments and cancer in Asia and European countries (Fakuda et al., 2003). In addition, walnuts are popular ingredients in baked foods and are frequently served in-shell during fall and winter seasons. They are mostly consumed after drying but undried and just harvested walnuts are also popular in the production places.

Being a dry fruit, walnut has an inherent potential for prolonged storage. However, its shelf- life is governed by the physical characteristics of in-shell nuts, moisture content of the kernels and microbial status of the kernels after shelling. Shell morphology with respect to its surface (rough/porous), suture (tight/corky) and seal (split/tight) are also important parameters, which determine the shelf-life potential. Porous suture and loose seal provide an easy entry for microorganisms and acts as a foci of infection in storage. In addition, due to the unscientific methods of harvesting and storage, these dried walnuts are prone to deteriorating effects of storage microorganisms, especially the xerophilic fungal species, which flourish very well on them and may deteriorate their quality. Moreover, the in-shell walnuts are usually sun-dried, and stored in traditional gunny bags or heaped as such on the ground till they are marketed or processed, which makes them more vulnerable to the huge diversity of soil borne opportunistic microbes especially the fusarial species. Some of these fusarial species may be toxigenic and produce mycotoxins during storage. Further, since walnuts contain high concentration of nutrients like fats, proteins, minerals, vitamins and a substantial quantity of dietary fibres, it is anticipated that they may form a very good substrate for the growth of a large number of moulds, which are known to stimulate the mycotoxin production. In view of this, an investigation was initiated to determine the contamination of fusarial toxins viz., zearalenone (ZEA), zearalenol (ZAL) and deoxynivalenol (DON) from the market samples of in-shell walnuts.

\section{Materials and Methods}

Extraction of fusarial toxins from walnut kernels

Market samples of in-shell walnuts were analysed for zearalenone (ZEA), zearalenol (ZAL) and deoxynivalenol (DON) by using modified multimycotoxin method developed by Roberts and Patterson (1975). In this method, $25 \mathrm{~g}$ of finely ground in-shell kernels were taken in an Erelenmeyer flask (250 ml capacity) and $100 \mathrm{ml}$ mixture of acetonitrile and $4 \%$ potassium chloride $(90: 10 \mathrm{v} / \mathrm{v})$ was added to it. The flask containing mixture was kept for horizontal shaking on a rotary shaker for 30 minutes. Thereafter, extract was filtered through Whatman no. 41 filter paper and the filtrate was defatted twice with $50 \mathrm{ml}$ iso-octane in a separating funnel (250ml capacity). When the layers separated clearly, upper iso-octane layer was discarded and the lower acetonitrile layer was re-extracted with $50 \mathrm{ml}$ iso-octane. Discarded the upper lipid containing layer and added $12.5 \mathrm{ml}$ distilled water to the lower acetonitrile layer. This layer was extracted thrice by using $20 \mathrm{ml}$ chloroform each time. Lower chloroform - acetonitrile layer was collected in a conical flask and drained through Whatman no. 41 filter paper having a bed of anhydrous sodium sulphate. The extract was collected in a beaker and marked as extract I. The aqueous layer left in the separating 


\section{International Journal of Science and Research (IJSR) \\ ISSN (Online): 2319-7064 \\ Index Copernicus Value (2013): 6.14 | Impact Factor (2014): 5.611}

funnel was acidified with $1 \mathrm{ml}$ of $1.0 \mathrm{~N}$ HCL and the acidic mycotoxins were extracted from it thrice by using $10 \mathrm{ml}$ chloroform each time. Lower chloroform layers were combined, passed through anhydrous sodium sulphate bed, collected in a beaker and marked as extract II. Extracts I and II were combined and then evaporated to dryness on a water bath. After evaporation, the residue was dissolved in $1 \mathrm{ml}$ of chloroform and stored in small screw cap vials for qualitative and quantitative estimation of fusarial toxins.

\section{Detection of fusarial toxins}

For detection of ZEA, ZAL and DON, aliquots of sample extract $(50 \mu \mathrm{l})$ were spotted on TLC plates along with the standards and developed in a solvent system consisting of toluene : ethyl acetate : formic acid (6:3:1, v/v/v). After drying, plates were observed under long wave UV light. ZEA spots were located as blue green fluorescent spots; ZAL spots were located as light blue fluorescent spots and that of DON as sky blue spots. Confirmation was done by spraying the plates with freshly prepared saturated solution of aluminium chloride in 95\% ethanol and then heating it at $120^{\circ} \mathrm{C}$ for $10 \mathrm{~min}$. The spots of ZEA, ZAL and DON became brighter in appearance.

\section{Quantitative estimation of fusarial toxins}

Quantitative analysis of ZEA, ZAL and DON was done through high performance liquid chromatography. The analytical equipment for HPLC (CLASS-LC10 SHIMADZU) consisted of a liquid chromatographic pump LC-10AT, an auto-injection system SIL-10A with a $50 \mu \mathrm{l}$ sample loop, and a variable wavelength absorbance UV VIS detector SPD -10 set at $365 \mathrm{~nm}$. The analytical column was C-18 (250 x $4.6 \mathrm{~mm}$ ), filled with ODS (M), RP-18 material, $5 \mu \mathrm{m}$ particle size (Merck).

Analysis of ZEA was done by using modified method of Scudamore and Patel (2000). For this, a variable wavelength absorbance fluorescent detector set at $274 \mathrm{~nm}$ excitation and $440 \mathrm{~nm}$ emission was used. The mobile phase consisted of acetonitrile : water $(55: 45, \mathrm{v} / \mathrm{v})$ and was used at a flow rate of $0.5 \mathrm{ml} / \mathrm{min}$. Injection volume for extract solution was 10 and $20 \mu \mathrm{l}$ for different samples. Analysis was performed at room temperature $\left(25-30^{\circ} \mathrm{C}\right)$ and quantification of ZEA was done by comparison of the retention time ( $9.5 \mathrm{~min}$ ) and peak area observed in the ZEA standard with those observed for samples (Figure 1a).

For analysis of ZAL, method of James et al. (1982) was modified and used. In this method, a variable wavelength absorbance UV detector set at $236 \mathrm{~nm}$ was used. The mobile phase consisted of methanol : water $(75: 25 \mathrm{v} / \mathrm{v})$ and was used at a flow rate of $1 \mathrm{ml} / \mathrm{min}$. Injection volume for extract solution was 2, 3 and $5 \mu$ for different samples. Analysis was performed at room temperature $\left(25-30^{\circ} \mathrm{C}\right)$ and quantification was done by comparison of the retention time (5.8 min) and peak area observed in the ZAL standard with that observed in samples (Figure 1b).

Quantitative analysis of deoxynivalenol (DON) was done by following the method of Golinski et al. (1996) after modification. In this case, a variable wavelength absorbance UV detector set at $229 \mathrm{~nm}$ was used. The mobile phase consisted of methanol: water $(85: 15 \mathrm{v} / \mathrm{v})$ at a flow rate of 1 $\mathrm{ml} / \mathrm{min}$ and the retention time was $2.94 \mathrm{~min}$. Injection volume for extract solution was 5 and $7 \mu$ for different samples. Analysis was performed at room temperature (25$30^{\circ} \mathrm{C}$ ) and quantification of DON was done by comparing the retention time and peak area observed in the DON standard with that observed in samples (Figure1c).

\section{Results}

\section{Detection of zearalenone}

Zearalenone was detected as an important toxic contaminant in some of the investigated samples. From a total of 30 samples of select grade of walnuts that were screened for this fusarial toxin, $63.33 \%$ were found to be positive. Quantitative analysis by HPLC showed that the range of contamination in the ZEA positive samples varied between 1.11 and $9.57 \mu \mathrm{g} / \mathrm{g}$ (Table 1). Earlier, Abdel-Hafez and Saber (1993) reported $125 \mu \mathrm{g}$ of $\mathrm{ZEA} / \mathrm{kg}$ in walnuts from Egypt. But in a survey conducted in Germany, ZEA has been detected in small amounts in various fruits and nuts (Schollenberger et al., 2005).

\section{Detection of zearalenol}

Zearalenol is an important secondary metabolite produced by various Fusarium species. HPLC analysis of in-shell walnut kernels showed that only $13.33 \%$ of samples were contaminated with ZAL and the amount of contamination varied from $5.42-11.49 \mu \mathrm{g} / \mathrm{g}$ of the sample. So far, there is no report of ZAL contamination from walnuts and other nuts but it has been frequently reported from other food products (Richardson et al. 1984).

\section{Detection of deoxynivalenol}

Deoxynivalenol, also known as vomitoxin or DON, is produced by various Fusarium species (Golinski et al., 1996; Hossein and Bagheri, 2012). DON belongs to the class trichothecenes of the type $B$ group. It is most widely distributed fusarial toxin and is associated with nervous system disturbance, irritation of the gastrointestinal tract and haemorrhage in the consumers (Rotter et al., 1996). As depicted in table 1, only one sample of in-shell walnut kernels was detected to be positive for this contaminant. However, through HPLC analysis, this sample was detected to possess high level of DON contamination (Table 1). Occurrence of DON in food and feed is also potential marker of the occurrence of other mycotoxins (Sobrova et al., 2010).

\section{Co-occurrence of fusarial toxins}

Perusal of data given in table 1 also shows that three samples (IS-7, IS-14 and IS-23) of in-shell walnut kernels showed co-occurrence of zearalenol and zearalenone. Among these two fusarial toxins, detected amount of ZAL contamination was more than that of ZEA (Figure 2). ZAL is known to co-occur naturally in dried commodities with other fusarial toxins and is about three to four times more oestrogenic than ZEA and may contribute to hyperestrogenism (Hagler et al.,1979). In the present investigation, only one sample (IS-5) of in-shell walnuts showed co-occurrence of DON and zearalenone (Figure 2). Similar combination of fusarial toxins has been observed in different plant products by various workers (Fazekas et al., 1996; Gonzalez et al., 1999; Sardjono et al., 1998).

\section{Volume 5 Issue 2, February 2016}




\section{International Journal of Science and Research (IJSR) \\ ISSN (Online): 2319-7064 \\ Index Copernicus Value (2013): 6.14 | Impact Factor (2014): 5.611}

\section{Discussion}

During the present investigation, very high levels of ZEA were detected from the samples of in- shell walnut kernels $(1.11-9.57 \mu \mathrm{g} / \mathrm{g})$, which are popularly consumed in all parts of India. In view of the oestrogenic activities of ZEA (Herrman and Trigo-Stockii, 2002), its detection in walnut kernels may prove dangerous to the consumers. From J\&K State, ZEA contamination has not been so far reported from walnuts but it has been reported from some dried herbals (Koul and Sumbali,2008) and dried vegetables (Sodhi and Sumbali, 2012). ZEA has been shown to be hepatotoxic, immunotoxic, genotoxic and haemotoxic (Lioi et al., 2004; Maaroufi et al., 1996; Zinedine et al., 2007). Although ZEA is ubiquitous and toxic, it is dangerous for human and animal health, only when it is absorbed in high amounts or over long time of exposures (Zinedine et al., 2007). Gray et al. (2004) discovered oestrogenic effects caused in some post-menopausal woman due to ZEA contamination in ginseng products. Some studies have even demonstrated that ZEA has the potential to stimulate growth of human breast cancer cells containing estrogen response receptors (Ahamed et al., 2001, Yu et al., 2005). The International Agency for Research on Cancer (International Agency for Research on Cancer, 2002) has classified zearalenone as group 3 carcinogen. The Joint FAO/WHO Exert Committee on Food Additives (JECFA) has estabilished a provisional maximum tolerable daily intake for ZEA to be $0.5 \mu \mathrm{g} / \mathrm{kg}$ body weight (The Joint FAO/WHO Expert Committee on Food Additives, 2000). In view of the reported toxicity, such high amounts of ZEA from walnut kernels may prove a health hazard if preventive steps are not taken into consideration.

Detection of very high amount of ZAL in some samples suggests that walnut kernels are good substrate for its production. Some of the kernel samples even showed cooccurrence of zearalenol and zearalenone (Figure 2). ZAL is known to co-occur naturally in dried commodities with other fusarial toxins and is about three to four times more oestrogenic than ZEA and may contribute to hyperestrogenism (Hagler et al.,1979). Zearalenol metabolites cause cytotoxicity by inhibiting cell viability, protein and DNA synthesis and inducing oxidative damage and expression of stress proteins (Othmen et al., 2008). Just like ZEA, the total intake for this metabolite should not exceed $0.5 \mu \mathrm{g} / \mathrm{kg}$ of body weight (Codex Committee on Food Additives and Contaminants, 2000).

Detection of DON in one of the samples of walnut kernels again suggests its susceptibility as a substrate for fusarial toxins. Presence of DON in walnut kernels is quite alarming as it can affect the immune system of consumers and make them susceptible to microbial diseases. So far, there is very little information on the contaminant DON in nuts and dried fruits (Boutrif and Caner, 1998, Council for Agricultural Science and Technology, 2003; Food and Agriculture Organisation, 1997) but it is the most widely distributed fusarial toxin reported from other dried agricultural commodities (Bhat et al., 2010; Gouze et al., 2006; Koul and Sumbali, 2008; Sobrova et al., 2010; Sodhi and Sumbali, 2012). In the present investigation, walnut sample showing contamination of DON also showed co-occurrence of ZEA (Figure 2).Thuvander et al.(1999) studied the combined exposure of trichothecenes and concluded that it resulted mainly in additive, antagonistic and synergistic effects. Canady et al. (2001) reported that the World Health Organization Joint Expert Committee on Food Additives has evaluated the safety of DON for human, and it has established a provisional maximum tolerable daily intake (PMTDI) for DON to be $1-\mu \mathrm{g} / \mathrm{kg}$ body weight.

\section{Conclusion}

Detection of three most important fusarial toxins (ZEA, ZAL and DON) from some of the investigated samples suggests that in-shell walnut kernels are quite susceptible to their formation. In view of these observations, the in-shell walnut kernels are not completely safe for human consumption. Although very few samples showed cooccurrence of fusarial toxins, yet their accumulation is expected to create adverse health problems to the consumers. Therefore, levels of these toxins in walnuts should be kept below the permissible limits by using postharvest management strategies that could restrain fungal growth and formation of their toxic metabolites. In addition, frequent analytical surveillance programme by food control agencies is highly recommended to control the incidence of mycotoxin contamination in walnut kernels.

\section{Acknowledgement}

The authors are thankful to Head, Department of Botany, University of Jammu for providing laboratory facilities.

\section{References}

[1] Abdel-Hafez, A.l.l. and Saber, S.M., 1993. Mycoflora and mycotoxin of hazelnut (Corylus avellana L.) and walnut (Juglans regia L.) seeds in Egypt. Zentralblatt fur Mikrobiologie 148:137-147.

[2] Ahamed, S., Foster, J.S., Bukovsky, A. and Wimalasena, J., 2001. Signal transduction through the Ras/Erk pathway is essential for the mycoestrogen zearalenone-induced cell-cycle progression in MCF-7 cells. Molecular Carcinogenesis 30: 88-98.

[3] Bhat, R., Rai, R.V. and Karim, A.A., 2010. Mycotoxins in food and feed : present status and future concern. Comprehensive Review of Food Science and Food Safety 9: 57-81.

[4] Boutrif, E. and Caner, C., 1998. Mycotoxin prevention and control. FAO programmes. Revue de Medecine Veterinaire 149: 681-694.

[5] Canady, R.A., Coker, R.D., Egan, S.K., Krska, R., Kuiper-Goodman, T., Olsen, M., Pestka, J., Resnik, S. and Schlatter, J., 2001. Deoxynivalenol. In: Safety evaluation of certain mycotoxins in food. Geneva: World Health Organisation 420-529.

[6] Codex Committee on Food Additives and Contaminants, 2000. Posting date. Joint FAO/WHO Expert Committee on Food Additives: Position paper on zearalenone. Publication CCFAC 00/19. Codex Alimentarius Commission, Rome, Italy.

[7] Council for Agricultural Science and Technology, 2003. Mycotoxins: Risks in plant, animal, and human systems. Task Force Report No. 139.,Council for 
Agricultural Science and Technology, Ames, IA. Available from http://www.castscience.org/cast/pb/Mycotoxins.pdf.

[8] Fakuda, T., Ito, H. and Yoshida, T., 2003. Antioxidative polyphenols from walnuts (Juglans regia L.). Phytochemistry 63: 795-801.

[9] Food and Agriculture Organisation, 1997. Worldwide regulations for Mycotoxins, 1995. A compendium. FAO Food and Nutrition: Paper 64 (Rome: Food and Agriculture Organization of the United Nations).

[10] Fazekas, B., Kis, M. and Hajdu, E.T., 1996. Data on the contamination of maize with fumonisin B1 and other fusario toxins in Hungary. ActaVeterinaria Hungarica 44: 25-37.

[11] Golinski, P., Perkowski, J., Kostecki, M., Szezsna, J.G. and Chelkowski, J., 1996. Fusarium species and Fusarium toxins in wheat in Poland. A comparison with neighbour countries. Sydowia 48: 12-22.

[12] Gonzalez, H.H.L., Martinez, E.J., Pacin, A.M., Resnik, S.L. and Sydenham, E.W., 1999. Natural cooccurrence of fumonisins, deoxynivalenol, zearalenone and aflatoxins in field trial corn in Agrentina. Food Additives and Contaminants 16: 565-569.

[13] Gouze, M.E., Laffitte, J., Rouimi, P., Loiseau, N., Oswald, I.P. and Galtier, P., 2006. Effect of various doses of deoxynivalenol on liver xenoblotic metabolizing enzymes in mice. Food and Chemical Toxicology 44: 476-483.

[14] Gray, S.L., Lackey, B.R., Tate, P.L., Riley, M.B. and Camper, N.D.,2004. Mycotoxins in root extracts of American and Asian ginseng bind estrogen receptors $\alpha$ and $\beta$. Experimental Biology and Medicine 229: 560568.

[15] Hagler, W.M., Mirocha, C.J., Pathre, S. V. and Behrens, J.C., 1979. Identification of the naturally occurring isomers of zearalenol produced by Fusarium roseum 'Gibbosum' in rice culture. Applied and Environmental Microbiology 849-853.

[16] Herrman, T. and Trigo-Stockli, D., 2002. Mycotoxins in feed grains and ingredients MF-2061, Feed manufacturing Kansas State University.

[17] Hosseini, S.S. and Bagheri, R., 2012. Some major mycotoxin and their mycotoxicoses in nuts and dried fruits. International Journal of Agronomy and Plant Production 3: 179-184.

[18] International Agency for Research on Cancer, 2002. IARC Monographs on the Evaluation of Carcinogenic Risks to Humans,. 82, Some Traditional Herbal Medicines, Some Mycotoxins, Naphthalene and Styrene. Lyon, France: World Health Organization (WHO), IARC Press.

[19] James, L.J., Mc Girr, L.G. and Smith, T.K., 1982. High pressure liquid chromatography of zearalenone and zearalenol in rat urine and liver. Journal Association of Official Analytical Chemists 65: 8-13.

[20]Koul, A. and Sumbali, G., 2008. Detection of aflatoxins B1 and B2 from medicinally important dried rhizomes. Journal of Mycology and Plant Pathology 38: 531-533.

[21] Lioi, M.B., Santoro, A., Barbieri, R., Salzano. and Ursini, M.V., 2004. Ochratoxin and zearalenone: a comparative study on genotoxic effects and cell death induced in bovine lymphocytes. Mutation Research 557: 19-24.

[22] Maaroufi, K., Chekir, L., Creppy, E.E., Ellouz, F. and Bacha, H.,1996. Zearalenone induces modifications in haematological and biochemical parameters in rats. Toxicon 34: 534-540.

[23] Othmen, Z.Q.B., Golli, E.E., Abid-Essefi, S. and Bacha, H., 2008. Cytotoxicity effects induced by zearalenone metabolites, zearalenol and zearalenol, on cultured vero cells. Toxicology 252: 72-77.

[24] Richardson, K.E., Hagler, W.M. and Hamilton, P.B., 1984. Method for detecting production of zearalenone, zearalenol, T-2 toxin and deoxynivalenol by Fusarium isolates. Applied and Environmental Microbiology 643-646.

[25] Roberts, B.A. and Patterson, .D.S.P., 1975. Detection of twelve mycotoxins in mixed animal feed stuff's using a novel membrane cleanup procedure. Journal Association of Official Analytical Chemists 58: 11781181.

[26] Rotter, B.A., Prelusky, D.B. and Pestka, J.J., 1996. Toxicology of deoxynivalenol (vomitoxin). Journal of Toxicology and Environmental Health 48: 101-105.

[27] Sabate, J., Fraser, G,E., Burke, K., Knutsen, S., Bennett, H. and Lindsted, K.D., 2003. Effect of walnut on serum lipid levels and blood pressure in normal men. New England Journal of Medicine 328: 603-607.

[28] Sardjono, N.A., Yasmashita, A. and Yoshizawa, T., 1998. Natural co-occurrence of aflatoxins and Fusarium mycotoxins (fumonisins, deoxynivalenol, nivalenol and zearalenone) in corn from Indonesia. Food Additives and Contaminants 15: 337-384.

[29] Schollenberger, M., Muller, H.M., Rufle, M., Suchy, S., Planck, S. and Drochner. W., 2005. Survey of Fusarium toxins in foodstuffs of plant origin marketed in Germany. International Journal of Food Microbiology 97: 317-326.

[30] Scudamore, K.A. and Patel, S., 2000. Survey for aflatoxins, ochratoxin A, zearalenone and fumonisns in maize imported into the United Kingdom. Food Additives and Contaminants 17: 407-416.

[31] Sobrova, P., Adam, V., Vasatkova, A., Beklova, M., Zeman, L. and Kizek, R., 2010. Deoxynivalenol and its toxicity. Interdisciplinary Toxicology 3: 94-99.

[32] Sodhi, H.K. and Sumbali, G., 2012. Occurrence of zearalenone, zearalenol and deoxynivalenol in some market samples of dried vegetables in $\mathrm{J} \& \mathrm{~K}$ state. Proceedings of the National Academy of Sciences 82: 531-535.

[33] The Joint FAO/WHO Expert Committee on Food Additives, 2000. Zearalenone In: Joint FAO/WHO Expert Committee on Food Additives (Ed.), Safetyevaluation of certain food additives and contaminants. WHO/FAO Food additives Series 44. IPCS International Program on Chemical Safety.WHO, Geneva.

[34] Yu, Z., Zhang, L., Wu, D. and Liu, F., 2005. Antiapoptotic action of zearalenone in MCF-7 cells. Ecotoxicology and Environmental Safety 62: 441446.

[35] Zinedine, A., Soriano, J.M., Molto, J.C. and Manes, J., 2007. Review on the toxicity, occurrence, 


\section{International Journal of Science and Research (IJSR) \\ ISSN (Online): 2319-7064 \\ Index Copernicus Value (2013): 6.14 | Impact Factor (2014): 5.611}

metabolism, detoxification, regulations and intake of zearalenone: An oestrogenic mycotoxin. Food and

Chemical Toxicology 45: 1-18.

Table 1: Zearalenone (ZEA), Zearalenol (ZAL) and Deoxynivalenol (DON) contamination detected from the in-shell kernels of walnuts

\begin{tabular}{|c|c|c|c|}
\hline \multirow{2}{*}{$\begin{array}{c}\text { In-shell } \\
\text { kernels }\end{array}$} & \multicolumn{3}{|c|}{ FUSARIAL TOXINS $(\mu \mathrm{g} / \mathrm{g})$} \\
\cline { 2 - 4 } & $\begin{array}{c}\text { Zearalenone } \\
\text { ZEA })\end{array}$ & $\begin{array}{c}\text { Zearalenol } \\
(\text { ZAL })\end{array}$ & $\begin{array}{c}\text { Deoxynivalenol( } \\
\text { DON })\end{array}$ \\
\hline IS-1 & - & - & - \\
\hline IS-2 & - & - & - \\
\hline IS-3 & - & - & - \\
\hline IS-4 & - & - & - \\
\hline IS-5 & 5.890 & - & 29.342 \\
\hline IS-6 & - & 7.326 & - \\
\hline IS-7 & 3.269 & 11.124 & - \\
\hline IS-8 & - & - & - \\
\hline IS-9 & - & - & - \\
\hline IS-10 & 2.201 & - & - \\
\hline IS-11 & 9.572 & - & - \\
\hline IS-12 & 9.396 & - & - \\
\hline IS-13 & - & - & - \\
\hline IS-14 & 4.107 & 5.421 & - \\
\hline IS-15 & 4.660 & - & - \\
\hline IS-16 & 2.943 & - & - \\
\hline IS-17 & 6.161 & - & - \\
\hline IS-18 & 3.316 & - & - \\
\hline IS-19 & 4.220 & - & - \\
\hline IS-20 & 5.080 & - & - \\
\hline IS-21 & 3.863 & - & - \\
\hline IS-22 & - & - & - \\
\hline IS-23 & 3.919 & 11.490 & - \\
\hline IS-24 & 4.536 & - & - \\
\hline IS-25 & 1.110 & - & - \\
\hline IS-26 & - & - & - \\
\hline IS-27 & - & - & - \\
\hline IS-28 & - & - & - \\
\hline IS-29 & - & - & - \\
\hline IS-30 & - & - & - \\
\hline Positive & 63.33 & 13.33 & - \\
samples (\%) & & & - \\
\hline & & - & - \\
\hline
\end{tabular}

-, not detected

Volume 5 Issue 2, February 2016 
International Journal of Science and Research (IJSR)

ISSN (Online): 2319-7064

Index Copernicus Value (2013): 6.14 | Impact Factor (2014): 5.611

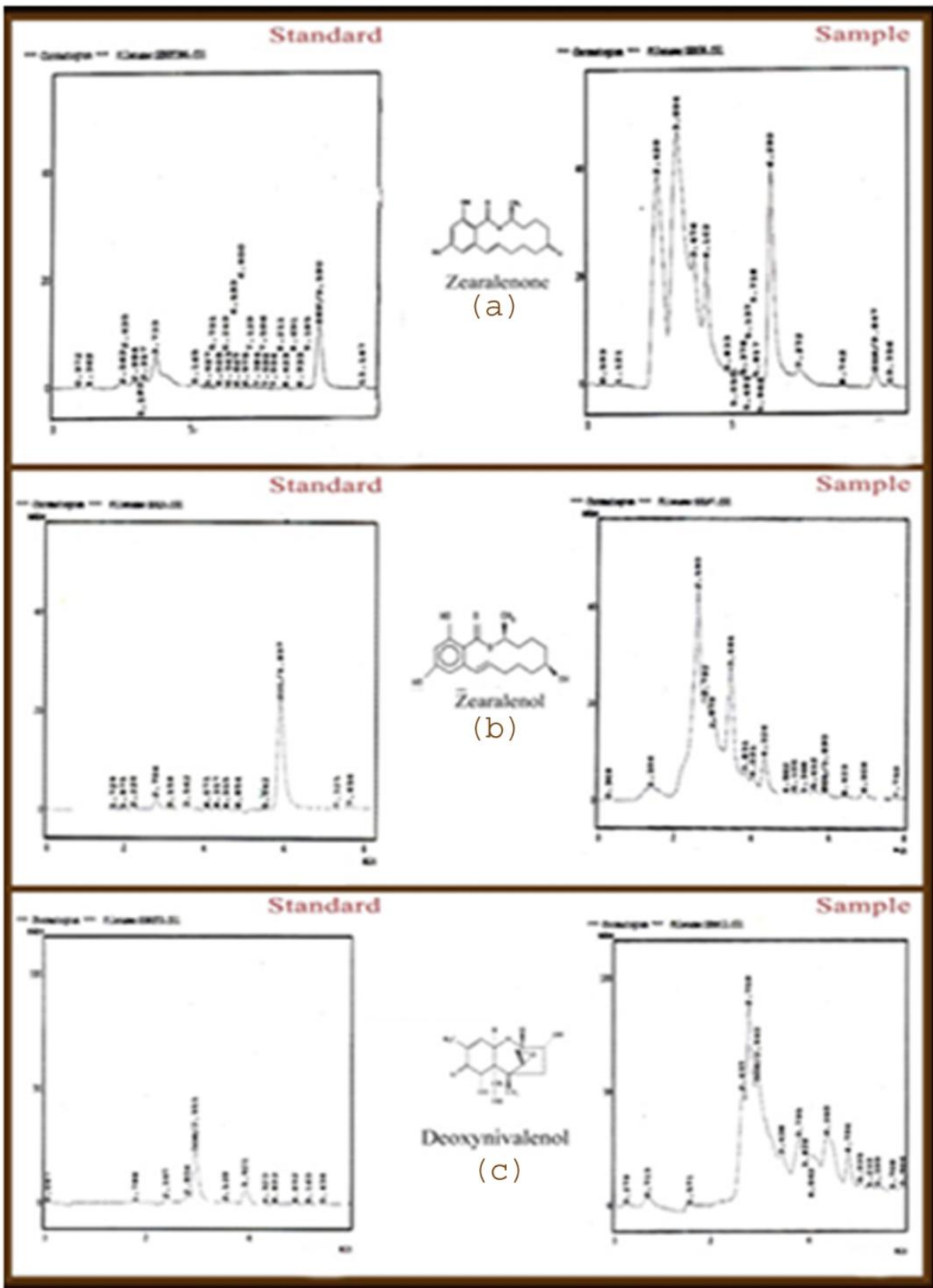

Figure 1: HPLC chromatograms of ZEA, ZAL and DON.

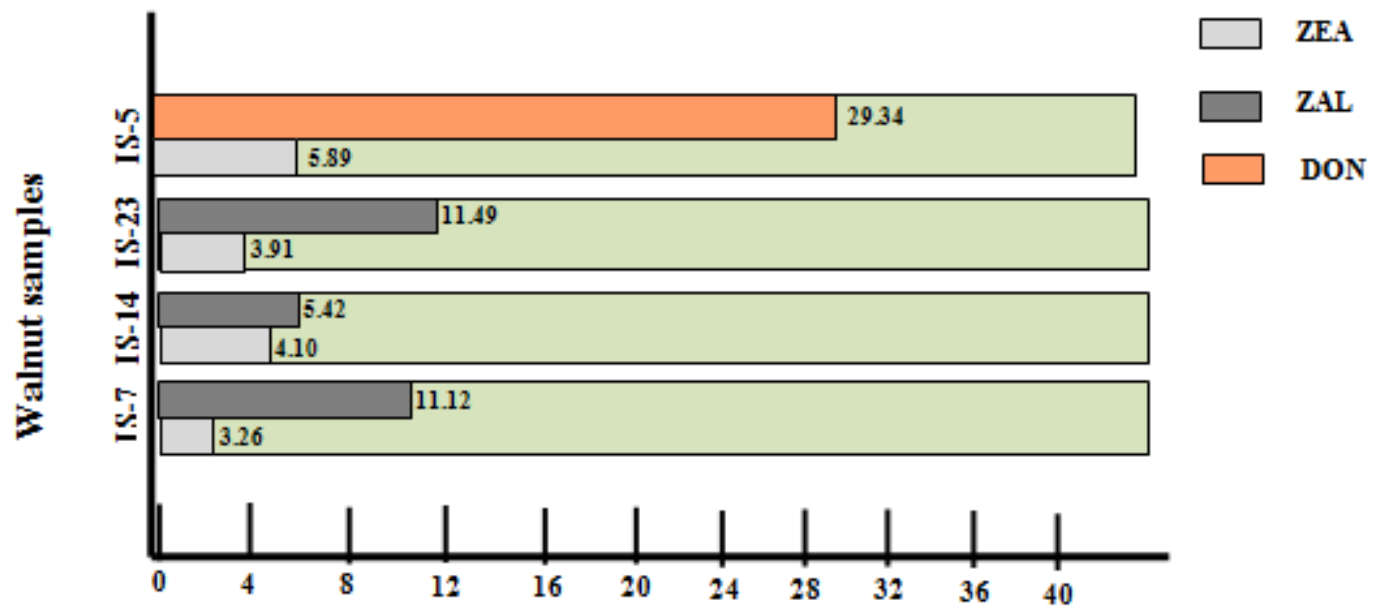

Figure 2: Co-occurrence of zearalenone (ZEA) and zearalenol (ZAL) and deoxynivalenol (DON) detected in the in-shell walnut kernels.

Volume 5 Issue 2, February 2016

www.ijsr.net 